\title{
PROTOCOL FOR PERIODONTAL TOOTH PREPARATION WITH ER-YAG LASER BEFORE FIXED PROSTHETIC TREATMENT
}

\author{
Plamen Nenkov ${ }^{1}$, Metodi Z. Abadzhiev ${ }^{1}$, Polina Velcheva ${ }^{2}$ \\ 1) Department of Prosthetic Dental Medicine, Faculty of dental medicine, \\ Medical University - Varna, Bulgaria. \\ 2) Department of Conservative Dental Treatment and Oral Pathology, Faculty \\ of dental medicine, Medical University - Varna, Bulgaria.
}

\section{ABSTRACT}

Purpose: Every clinician encounter isses with problematic periodontal tissue around teeth intended to be treatet prosthetically. Swollen, reddish, with deeper periodontal pockets and and impossible to dry up with air flow. Such teeth should be treated rapidly and minimally invasive. The purpose of this study was to create an algorithm for periodontal tooth preparation with Er-YAG laser before prosthetic treatment.

Material/Methods: It was used examination and diagnosis of teeth for the purpose of prosthodontic treatment according to the periodontal status by using UNC 15 perioprobe and electronic periodontal probe $\mathrm{Pa}-\mathrm{On}$ and Er-YAG dental laser. There were examined 216 periodontal units, 106 of them treated according to the suggested protocol. An innovative approach was used by considering all treated teeth suitable for impression by the visual indicator -periodontal margin condition (lack of inflammatory symptoms, lack of bleeding, lack of redness, presence of pink, dense gingiva. Record of the day with "pink gingiva" appear was made.

Results: 216 units measured with a conventional and electronic periodontal probe in inflammatory status and after periodontal treatment. It was registered a significant difference between the data from the conventional periodontal probe and the electronic one.

Teeth prepared for prosthetic treatment were 106. By using a blind randomized clinical trial, $50 \%$ of them were prepared for prosthetic impression by using ultrasonic and the other half by using Er-YAG laser.

Teeth prepared for Prosthodontic impression are heathy between 2 nd and 7 th day after preparation $(61.54 \%$ -2nd day; $38.46 \%$ - 7th day) while the controlled group is between the 14 th and the 21 st day $(33.33 \%-14$ th day; $62.96 \%$ - 21st day). The total amount of attachment gain in such a short period of time by the protocol suggested by the authors is $1 \mathrm{~mm}$.

Conclusions: Considerable dental units show difference in periodontal pocket depth measurement to such degree that could lead to misdiagnosis and unnecessary treatment. Great difference is observed mainly between gingival pocket depth and superficial periodontitis.
Keywords: Periodontal preparation for Prosthetic treatment, Prosthetic impression, Er-YAG laser, periodontal probe, periodontal pocket depth, $\mathrm{Pa}-\mathrm{On}$,

\section{INTRODUCTION}

During the daily routine practice we encounter teeth predetermined to be pontics but periodontal tissues around are not suitable for prosthetic impression. The quality of impressions taken from teeth with compromised periodontal tissue with inflammation are prerequisite for poor dental technician work.

There are many studies that present different periodontal probes and the difference among them [1] but there is not enough evidence concerning the exact consequences for misdiagnosis and the total time needed for precise diagnosis. This is the reason for studying this matter and summing up the differences between one of the most frequently used periodontal probes - UNC 15 and an electric one $-\mathrm{PaOn}{ }^{\circledR}$ periodontal probe Orange dental.

In addition to the exact diagnosis, there is a need for periodontal tissue preparation prior to prosthodontic impression, especially in cases with signs of gingival inflammation that could obstruct taking of an impression and extend the time of dental treatment [2]. There is not enough information for periodontal tissue preparation, and there is insufficient literature evidence for any kind of protocol for such a preparation that could accelerate treatment and minimize unpleasant sensation. This is the reason why a protocol for periodontal tissue preparation with Er-YAG laser before fixed prosthetic treatment should be developed.

\section{MATERIALS AND METHODS}

Examination and diagnosis of teeth for the purpose of prosthodontic treatment is accomplished, according to the Periodontal status.UNC 15 perio-probe and electronic periodontal probe $\mathrm{Pa}-\mathrm{On}$ are used, comparison of the measurement profiles of the patients is made and the analysis of the eventual consequences according to the diagnosis data taken.The Gingival Bleeding Index - Ainamo\& Bay is also examined, as well as O'Leary's plaque index. 
Fig. 1. Comparison between two of the most frequently used hand peri-probes and the electronic Pa-On (from left to right - UNC15, Pa-On, CPITN)

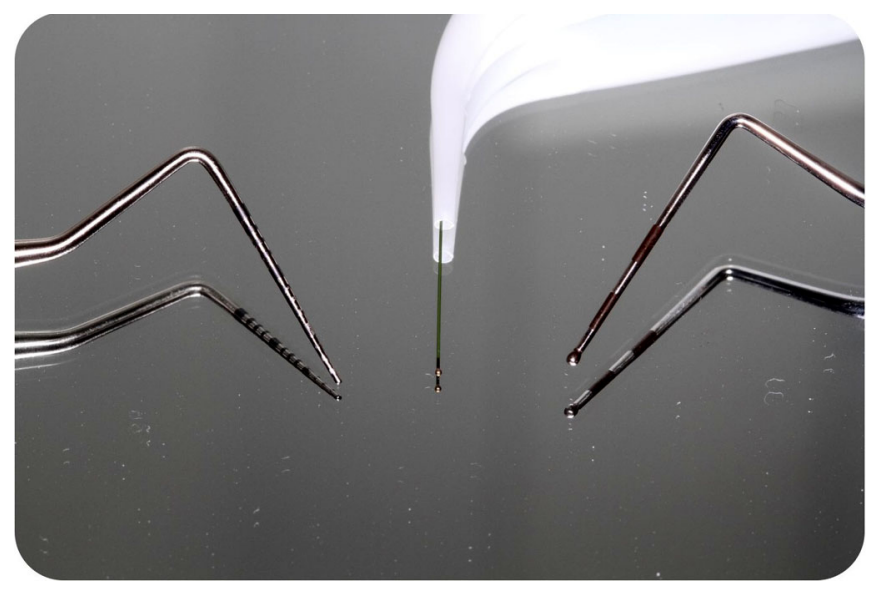

The method of probing is conventional - probing with $1 \mathrm{~mm}$ step around each tooth and registering six of the deepest values [3]. Hand probe registration of the data is done manually while with $\mathrm{Pa}-\mathrm{On}$, they are recorded automatically on the probe. Thet difference is significant for the ergonomics and time spent on diagnosis.

Er-YAG dental laser, in combination with ultrasonic, is applied for preparing teeth for prosthodontic impression and the results of the healing period are compared with the results of teeth prepared only with ultrasonic [4]. Patients in this comparison survey are chosen on randomized principle with a requirement for a relatively equal number of dental units treated in both groups. The total amount of examined 216 periodontal units is completed. 106 dental units are treated according to the suggested protocol created and developed by the authors in this study.

This protocol is consecutive work of the bio stimulating effect of the Er-YAG laser [5, 6, 7] on the soft tissues after ablation and removing of the inflamed tissue [8] and pursues prospective results.. The protocol includes unique laser settings, totally different from the factory settings and keeping the gentle biological touch to soft tissues. Factory setting of the laser includes: water $-75 \%$; power $-1,50 \mathrm{~W}$; energy $-50 \mathrm{~mJ}$; wave frequency $-30 \mathrm{~Hz}$. This is too powerful setting for gentle debridement. That is the reason why the research team developed by continuous tests the optimal settings for this task. Namely: water $-75 \%$; power $0,50 \mathrm{~W}$; energy $-50 \mathrm{~mJ}$; wave frequency $-10 \mathrm{~Hz}$.

After ultrasonic scaling, the developed algorithm includes the usage of three different laser tips in different anatomical locations of the periodontium [9].
Fig. 2. From left to right Laser tips a, b and c.

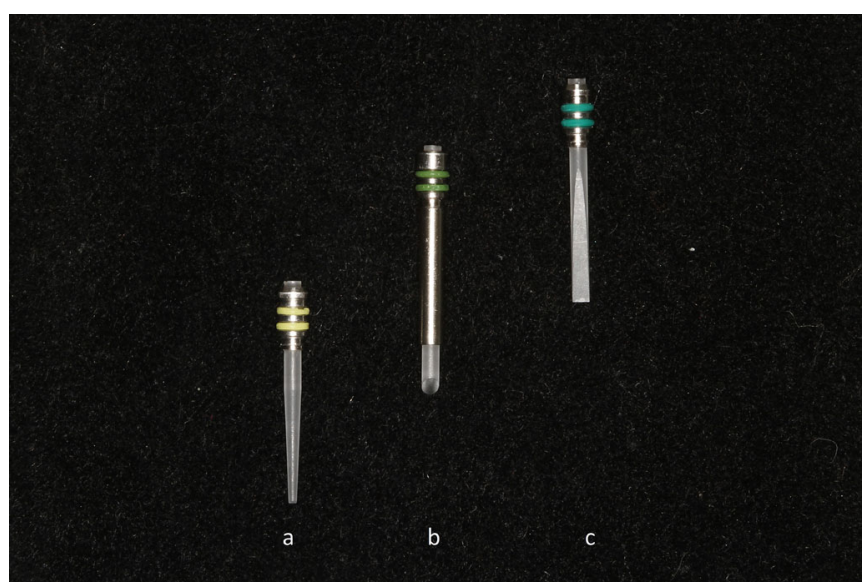

Laser tip from fig. 2a. is $0.6 \mathrm{~mm}$ in diameter $17.0 \mathrm{~mm}$ in length, yellow coded, made from sapphire with specific number AS7072X. The treatment area is the most apical zone of the periodontal tissue.

Laser tip from fig. $2 b$. is form the group of the specific tips, so-called Side fire tip. $1.3 \mathrm{~mm} \times 19.0 \mathrm{~mm}$ in length, green coded, made from sapphire with specific number AS7631X. The treatment area is the soft wall of the periodontal pocket, between the marginal edge and the most apical area of the sulcus or pocket.

Laser tip from fig. 2c. is Chisel tip, specific laser tips group. $1.3 \mathrm{~mm} \times 17.0 \mathrm{~mm}$ in length, made from sapphire with specific number AS7197X. The treatment area is the hard wall of the pocket - treating the necrotic cementum.

Fig. 3. The working area of each tip according to the suggested protocol. Tip a. from Fig. 2 treating area 1.; tip b. treating area between 1. and 3.; tip c. treating area 2.

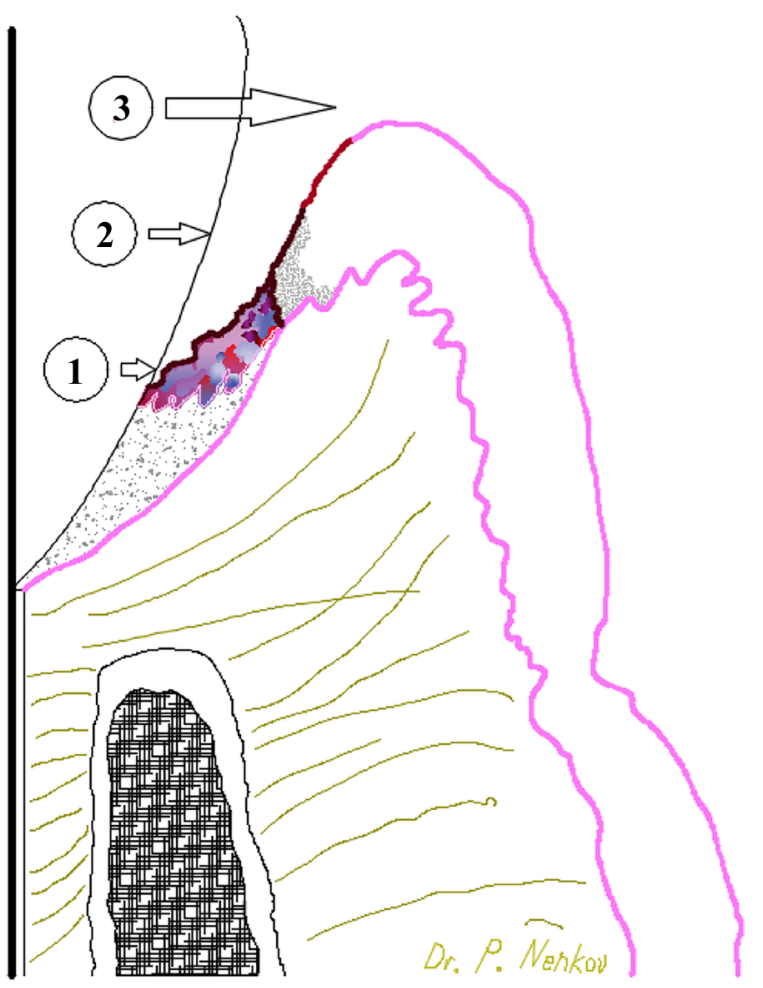




\section{RESULTS}

Results are derived from 216 teeth from 10 different patients, measured twice or 432 measured units. All patients meet criteria for research inclusion. Male or female adult patients, between 18 and 64 years of age, without any systemic disease, without medicine intake within the past 3 months, all patients should sign an informed consent and should have a high state of compliance. And last but not least all these patients should need prosthetic treatment of at least one tooth for a fixed crown or more than one tooth for a fixed prosthetic bridge. Measurements form the perioprobe UNC15, and Pa-On are compared as well as the time needed for measurement. All the data that is collected is recorded in MS Excel table for easy statistical comparison and according to the criteria diagnosis according to the pocket depth. Colour differentiation is made. Blue colour responds for pocket depth $0-3 \mathrm{~mm}$, green colour for depth between 3 and $5 \mathrm{~mm}$, and red colour for pockets over $5 \mathrm{~mm}$. Intermediate values between all these three basic colours are derivate colours of the same hue.

On the figures under the tables are visualized units of the teeth measured with UNC15 or Pa-On compared one over another for better clarity. Tables and charts are arranged by quadrants, starting from 1st (upper left side), 2nd (upper right side), 3rd (lower left side), and 4th lower right side). It is also shown dental units for crowns with letter " $\mathrm{K}$ ".

Fig. 4. one of the patient's MS-Excel chart.

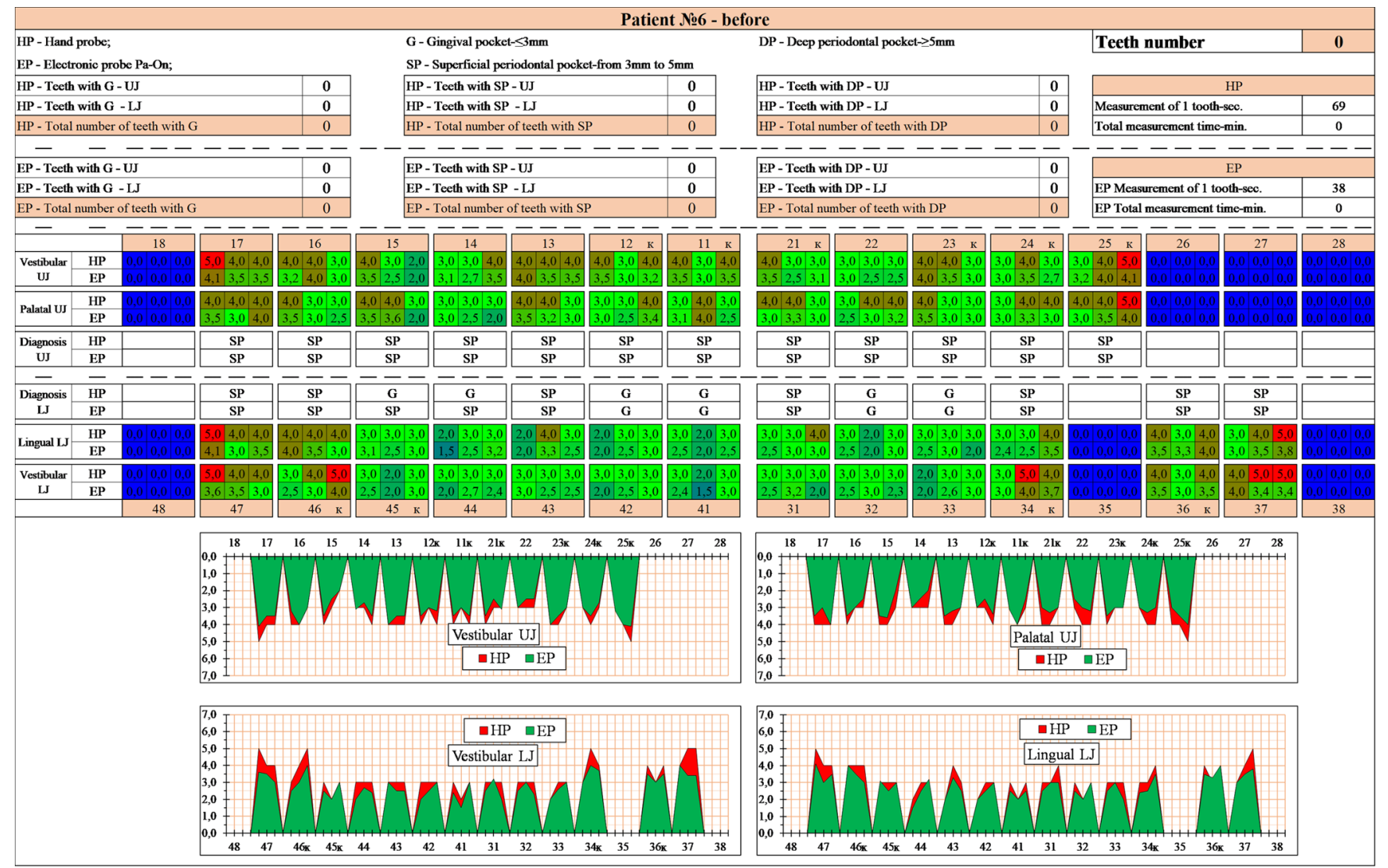

During the initial periodontal exam, pocket depth measurement was detected. $38.9 \%$ from all teeth are diagnosed with gingival pocket depth $<3 \mathrm{~mm} ; 54.6 \%$ with pocket depth $>3 \mathrm{~mm}$ and $<5 \mathrm{~mm}$; and $6.5 \%$ with pocket depth $>5 \mathrm{~mm}$, using UNC15 perio-probe. At the same time data recorded with $\mathrm{Pa}-\mathrm{On}$ probe were $39.8 \%<3 \mathrm{~mm} ; 52.8 \%$ $>3 \mathrm{~mm}$ and $<5 \mathrm{~mm}$; and $7.4 \%>5 \mathrm{~mm}$.

Fig. 5. Distribution of periodontal pockets accordind to the measured depth using hand-probe and electronic probe before treatment.

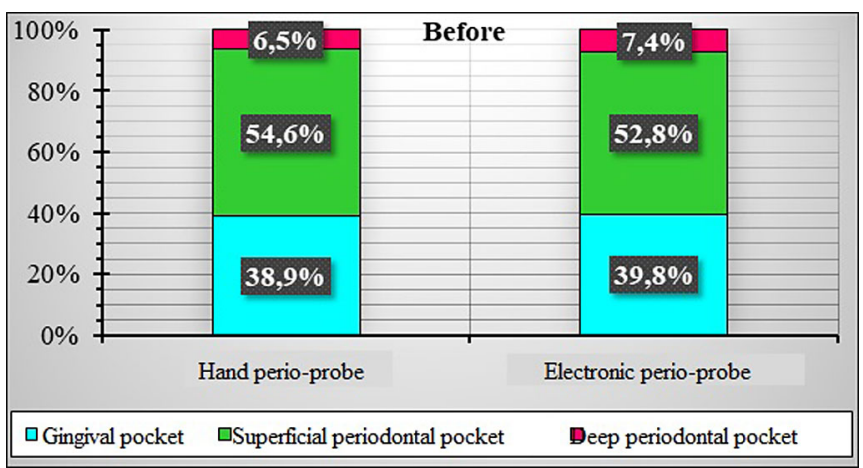


After the periodontal preparation the values were for UNC 15 probe: $76.9 \%<3 \mathrm{~mm} ; 22.7 \%>3 \mathrm{~mm}$ and $<5 \mathrm{~mm}$; and $0.5 \%>5 \mathrm{~mm}$. And for the electronic probe: $90.7 \%$ $<3 \mathrm{~mm} ; 8.3 \%>3 \mathrm{~mm}$ and $<5 \mathrm{~mm}$; and $0.9 \%>5 \mathrm{~mm}$.

Fig. 6. Distribution of periodontal pockets accordind to the measured depth using hand-probe and electronic probe after treatment.

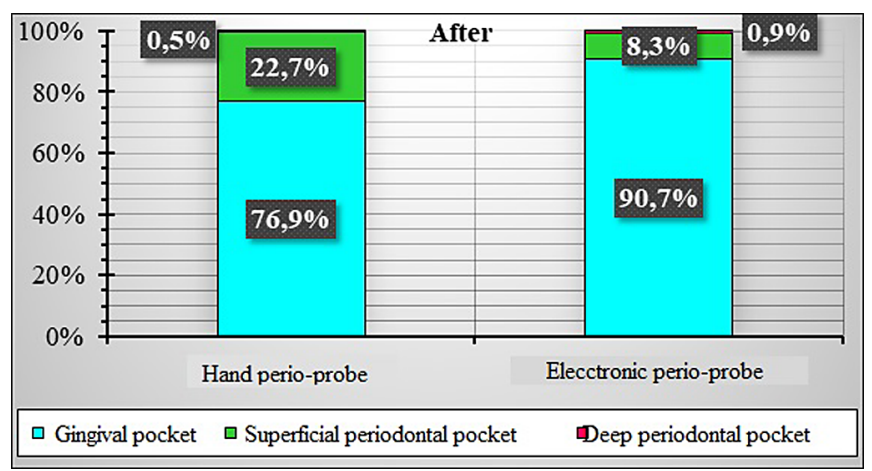

Tab. 1. Number of all dental units in all patients before and after treatment with a diagnosis of the periodontal tissue conditions around each tooth.

\begin{tabular}{|l|c|c|c|c|}
\hline \multirow{2}{*}{ Diagnosis } & \multicolumn{2}{|c|}{ Before } & \multicolumn{2}{c|}{ After } \\
\cline { 2 - 4 } & Hand probe & Electronic probe & Hand probe & Electronic probe \\
\hline Gingival pocket & $38,9 \%$ & $39,8 \%$ & $76,9 \%$ & $90,7 \%$ \\
\hline Superficial periodontal pocket & $54,6 \%$ & $52,8 \%$ & $22,7 \%$ & $8,3 \%$ \\
\hline Deep periodontal pocket & $6,5 \%$ & $7,4 \%$ & $0,5 \%$ & $0,9 \%$ \\
\hline
\end{tabular}

Tab. 2. Statistically processed dental units "before and after" with the time needed for measurement.

\begin{tabular}{|c|c|c|c|c|c|}
\hline Patient No. & Number of examined teeth & \multicolumn{2}{|c|}{$\tau$ - before, min } & \multicolumn{2}{c|}{$\tau$ - after, min } \\
\cline { 2 - 6 } & & Hand probe & Electronic probe & Hand probe & Electronic probe \\
\hline $\mathbf{1}$ & 18 & 19 & 8 & 20 & 8 \\
\hline $\mathbf{2}$ & 18 & 18 & 10 & 19 & 10 \\
\hline $\mathbf{3}$ & 14 & 14 & 7 & 31 & 6 \\
\hline $\mathbf{4}$ & 28 & 31 & 16 & 25 & 16 \\
\hline $\mathbf{5}$ & 23 & 27 & 14 & 26 & 13 \\
\hline $\mathbf{6}$ & 25 & 29 & 16 & 28 & 16 \\
\hline $\mathbf{7}$ & 26 & 29 & 16 & 19 & 11 \\
\hline $\mathbf{8}$ & 19 & 20 & 10 & 21 & 9 \\
\hline $\mathbf{9}$ & 20 & 21 & 10 & 25 & 13 \\
\hline $\mathbf{1 0}$ & 25 & 28 & 13 & $\mathbf{2 3}$ & $\mathbf{1 1}$ \\
\hline
\end{tabular}

On the upper right corner on fig. 4 is the count of all tested units per given patients as well as corresponding diagnosis according to the parameters set for periodontal pocket depth. It should be mentioned that the diagnosis is confirmed after positive or negative Gingival Bleeding Index (GBI - Ainamo and Bay). GBI is calculated for the whole dentition automatically on the electronic perioprobe $\mathrm{Pa}-\mathrm{On}$, and on the hand-probe is calculated by hand. The same is applied to the plaque index. 
Tab. 3. Gingival bleeding index (Ainamo and Bay) before and after treatment according to the authors' algorithm

\begin{tabular}{|c|c|c|c|c|c|c|c|c|c|c|}
\hline \multicolumn{10}{|c|}{ Bleeding index Inamo and Bay wih PaOn® } \\
\hline Patient No. & $\mathbf{1}$ & $\mathbf{2}$ & $\mathbf{3}$ & $\mathbf{4}$ & $\mathbf{5}$ & $\mathbf{6}$ & $\mathbf{7}$ & $\mathbf{8}$ & $\mathbf{9}$ & $\mathbf{1 0}$ \\
\hline Before, \% & 79 & 91 & 98 & 40 & 82 & 79 & 70 & 89 & 87 & 89 \\
\hline After, \% & 0 & 0 & 0 & 0 & 0 & 0 & 0 & 0 & 0 & 0 \\
\hline
\end{tabular}

Tab. 4. Plaque index (O’Leary) before and after treatment according to the authors' algorithm

\begin{tabular}{|c|c|c|c|c|c|c|c|c|c|c|}
\hline \multicolumn{10}{|c|}{ Plaque index O'Leary } \\
\hline Patient No. & $\mathbf{1}$ & $\mathbf{2}$ & $\mathbf{3}$ & $\mathbf{4}$ & $\mathbf{5}$ & $\mathbf{6}$ & $\mathbf{7}$ & $\mathbf{8}$ & $\mathbf{9}$ & $\mathbf{1 0}$ \\
\hline Before, \% & 83 & 100 & 100 & 51 & 91 & 91 & 75 & 77 & 86 & 78 \\
\hline After, \% & 9 & 13 & 15 & 0 & 9 & 8 & 5 & 12 & 9 & 11 \\
\hline
\end{tabular}

During the testing period for each patient is measured the time needed for measurement. All patient files are visualized on tables and charts.

Fig. 7. The time needed for measurement of every single patient before.

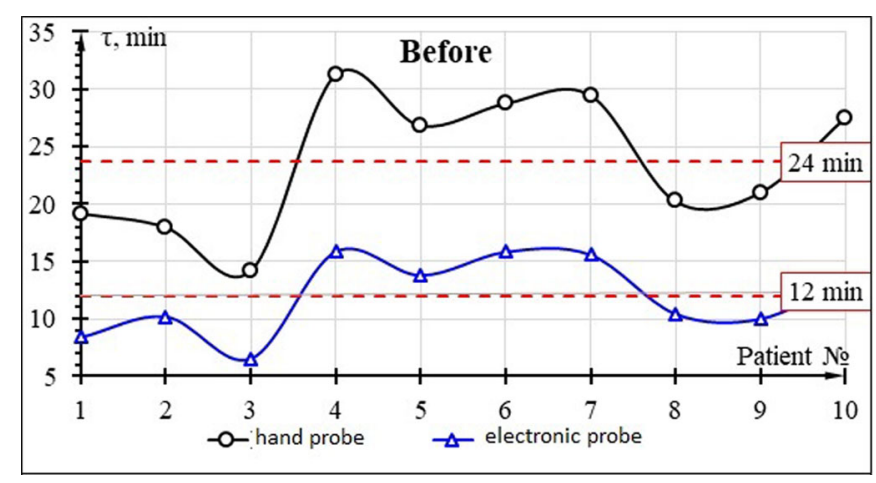

Precise diagnosis is only the initial side of the matter. A need for the development of a protocol for periodontal tissue preparation inspired the scientific team tho develop an algorithm prior prosthetic impression. Any stage of marginal periodontium inflammation could prevent the taking of a precise impression. After the protocol for periodontal tissue preparation prior to prosthetic impression, the most important indicators for achieving healthy periodontium is recorded - achieved healthy-pink gingiva on a respective day as well as gained attachment.
Fig. 8. The time needed for measurement of every single patient after.

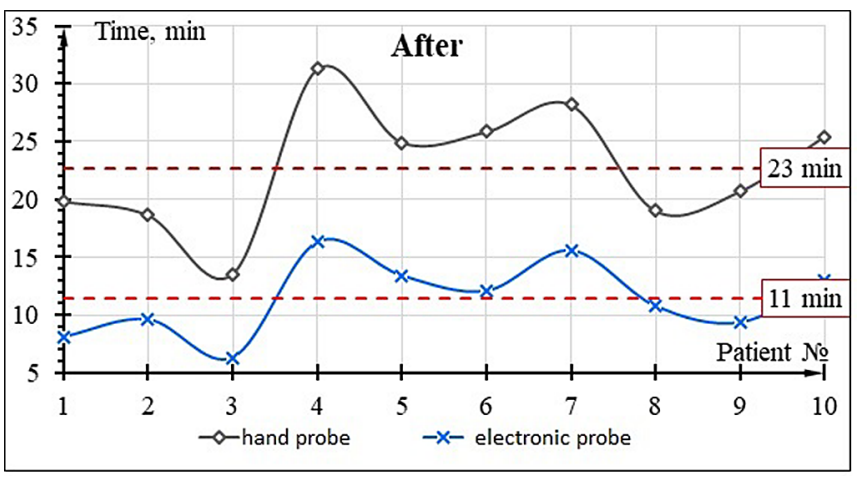

Teeth prepared for prosthetic impression only with ultrasonic [4] achieve healthy pink gingiva most recent (62.96\% of the cases) on the 21 st day, $33.33 \%$ on the 14 th day and $3.7 \%$ on the 7 th day. The total amount of attachment gained by this type of preparation is $0.57 \mathrm{~mm}$. Compared to the author's protocol, most of the cases acquire features of healthy-pink gingiva on 2 nd day $(62.54 \%)$, and $38.46 \%$ on the 7 th day of the preparation procedure. Average attachment gain is $1.00 \mathrm{~mm}$, twice more than the method used for comparison.

Tab. 5. Results from patients' charts after randomized preparation with ultrasonic or ultrasonic in combination with Er-YAG laser and the healing period till gaining pink healthy gingiva.

\begin{tabular}{|c|c|c|c|c|c|c|c|c|c|c|c|}
\hline \multirow{2}{*}{$\begin{array}{l}\text { Patient } \\
\text { No. }\end{array}$} & \multirow{2}{*}{$\begin{array}{c}\text { Teeth with } \\
\text { crowns }\end{array}$} & \multirow{2}{*}{$\begin{array}{c}\text { Preparation } \\
\text { method }\end{array}$} & \multicolumn{8}{|c|}{ Days after treatment } & \multirow{2}{*}{$\begin{array}{c}\text { Average } \\
\Delta \delta_{\text {pocket }}, \mathrm{mm}\end{array}$} \\
\hline & & & 2 inf & 7 inf & $14 \mathrm{inf}$ & $21 \mathrm{inf}$ & 2 pink & 7 pink & 14 pink & 21 pink & \\
\hline 1 & 8 & US & + & + & - & - & - & - & + & - & 0,49 \\
\hline 2 & 16 & US & + & + & + & - & - & - & - & + & 0,46 \\
\hline 3 & 14 & US and Er:YAG & - & - & - & - & + & - & - & - & 0,90 \\
\hline 4 & 2 & US & + & - & - & - & - & + & - & - & 0,48 \\
\hline 5 & 8 & US and Er:YAG & - & - & - & - & + & - & - & - & 1,13 \\
\hline
\end{tabular}




\begin{tabular}{|c|c|c|c|c|c|c|c|c|c|c|c|}
\hline $\mathbf{6}$ & 10 & US & + & + & - & - & - & - & + & - & 0,84 \\
\hline $\mathbf{7}$ & 6 & US and Er:YAG & - & - & - & - & + & - & - & - & 0,91 \\
\hline $\mathbf{8}$ & 18 & US & + & + & + & - & - & - & - & + & 0,60 \\
\hline $\mathbf{9}$ & 20 & US and Er:YAG & + & - & - & - & - & + & - & - & 1,04 \\
\hline $\mathbf{1 0}$ & 4 & US and Er:YAG & - & - & - & - & + & - & - & - & 1,00 \\
\hline
\end{tabular}

Tab. 6. Distribution of all units (teeth) with registered pink healthy gingiva and gained attachment by days and preparation methods used

\begin{tabular}{|c|c|c|c|c|c|c|c|}
\hline $\begin{array}{c}\text { Patient } \\
\text { No. }\end{array}$ & $\begin{array}{c}\text { Teeth with } \\
\text { crowns }\end{array}$ & Days after treatment & $\mathbf{2}$ pink & $\mathbf{7}$ pink & $\mathbf{1 4}$ pink & $\mathbf{2 1}$ pink & $\begin{array}{c}\text { Average } \\
\mathbf{\Delta} \boldsymbol{\delta}_{\text {pocket}}, \mathbf{~ m m}\end{array}$ \\
\hline $\mathbf{5}$ & 54 & Patients treated with US, \% & 0,00 & 3,70 & 33,33 & 62,96 & 0,57 \\
\hline $\mathbf{5}$ & 52 & Patients treated with US and Er:YAG, \% & 61,54 & 38,46 & 0,00 & 0,00 & 1,00 \\
\hline
\end{tabular}

Fig. 9. Healing period of patients treated with ultrasonic (red line) and patients treated with ultrasonic in combination with Er-YAG laser

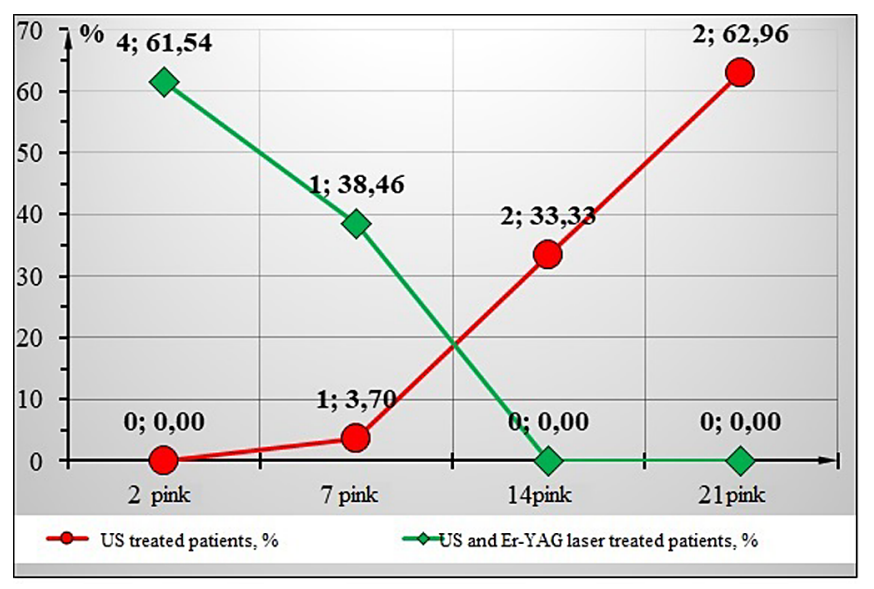

\section{DISCUSSION}

In dental medicine field, there is significant technological progress during the last decades that we could take advantage of in order to save our and our patients' time. A correct diagnosis could lead to considerable reduction of mistreated teeth in any given dental office and every dental society. A difference of $1 \mathrm{~mm}$ in the scale of periodontal space is significant and of great importance especially when it is achieved in a very short period of time.

The clinical study findings correspond to independent histological study [11], with results leading to the same conclusions. Future collaboration could be beneficial for the scienc in the field of periodontal laser treatment.

\section{CONCLUSIONS}

There is an existing technology that could lead to maximally facilitated and maximally ergonomic approach during the registration of periodontal pocket depth, bleeding index and plaque index. By comparing the achieced results with hand periodontal probe and electronic one, before and after periodontal preparation, we come to the conclusion that these measurement differences could lead to misdiagnosis. Misdiagnosis could lead to the wrong treatment or even unnecessary treatment and high-risk assessment [10]. Considerable teeth are misdiagnosed. We could conclude by the ancient Latin saying "Qui bene diagnostic bene curat" or "The one who diagnose better, treat better".

It is a logical conclusion that the presented algorithm is of great importance. There is a presence of significant difference in the results for the attachment gained as well as the reduction of periodontal pockets to physiological gingival sulcuses. And last but not least there is a much faster healing period after an initial inflammation of the marginal tissues.

\section{REFERENCES:}

1. Van der Zee E, Davis EH, Newman HN. Marking width calibration from tip and tine diameter of periodontal probes. J Clin Periodontol. 1991 Aug;18(7):516-20. [PubMed] [Crossref]

2. Abadzhiev M. Comparative research of the sub-gingival impression quality by fixed prosthesis using one and double cord retraction technique. $J$ of IMAB. 2009;10(2):52-54.
[Crossref]

3. Lindhe J, Lang NP, Karring T. Clinical Periodontology and Implant Dentistry. 5 edition. Wiley-Blackwell. April 7, 2008. [Internet]

4. Lang NP, Tan WC, Krähenmann MA, Zwahlen M. A Systematic Review of the Effects of Full-Mouth Debridement With and Without Antiseptics in Patients With Chronic Periodontitis. $J$ Clin Periodontol. 2008 Sep;35 (8
Suppl):8-21. [PubMed] [Crossref]

5. Aoki A, Watanabe H, Namiki N, Takiguchi T, Miyazawa Y, Suzuki M, et al. Periodontal soft tissue management with a high pulse rate Er:YAG laser. Int Congress Series. 2003 May; 1248:367-9. [Crossref]

6. Aoki A, Sasaki KM, Watanabe H, Ishikawa I. Lasers in nonsurgical periodontal therapy. Periodontology 2000. 2004; 36:59-97. [PubMed] [Crossref] 
7. Romeo U, Libotte F, Palaia G, Del Vecchio A, Tenore G, Visca P, et al. Histological in Vitro Evaluation of the Effects of Er:YAG Laser on Oral Soft Tissues. Lasers Med Sci. 2012 Jul; 27(4):749-53. [PubMed] [Crossref]

8. Krohn-Dale I, Bøe OE, Enersen M, Leknes KN. Er:YAG Laser in the Treatment of Periodontal Sites With Recurring Chronic Inflammation: A 12-month Randomized, Controlled
Clinical Trial. J Clin Periodontol. 2012 Aug;39(8):745-52. [PubMed] [Crossref]

9. Petersilka GJ, Ehmke B, Flemmig TF. Antimicrobial effects of mechanical debridement. Periodontology 2000. 2002; 28:56-71. [PubMed] [Crossref]

10. Lang NP, Suvan JE, Tonetti MS. Risk Factor Assessment Tools for the Prevention of Periodontitis Progression a Systematic Review. J Clin Periodontol. 2015 Apr;42(16):59-70. [PubMed] [Crossref]

11. Kazakova RT, Tomov GT, Kissov CK, Vlahova AP, Zlatev SC, Bachurska SY. Histological Gingival Assessment after Conventional and Laser Gingivectomy. Folia Med (Plovdiv). 2018 Dec 1;60(4):610-616. [PubMed] [Crossref]

Please cite this article as: Nenkov P, Abadzhiev MZ, Velcheva P. Protocol for periodontal tooth preparation with Er-YAG laser before fixed prosthetic treatment. J of IMAB. 2020 Jul-Sep;26(3):3271-3277.

DOI: https://doi.org/10.5272/jimab.2020263.3271

Received: 07/06/2019; Published online: 05/08/2020

\section{Address for correspondence:}

Plamen Nenkov

Department of Prosthetic Dental Medicine, Faculty of dental medicine, Medical University - Varna,

63, G. Rakovski str., Varna, Bulgaria.

E-mail: pl.nenkov@gmail.com, 